\title{
A STUDY OF NO SUTURE, NO GLUE CONJUNCTIVAL AUTOGRAFT SURGERY FOR PTERYGIUM
}

\author{
Suma C1, Manjula Y. M²
}

${ }^{1}$ Senior Resident, Department of Ophthalmology, BGS Global Institute of Medical Sciences and Hospital, Bangalore. ${ }^{2}$ Assistant Professor, Department of Ophthalmology, BGS Global Institute of Medical Sciences and Hospital, Bangalore.

\section{ABSTRACT}

\section{BACKGROUND}

The aim was to study the surgical outcome in no suture, no glue conjunctival autograft pterygium surgery.

\section{MATERIALS AND METHODS}

This was a prospective interventional study. 30 eyes of 30 patients with primary pterygium that came to the outpatients department at BGS GIMS, Bangalore from June 2014 to June 2015 were included in the study. After excision of pterygium and corneal scraping the recipient bed was allowed to bleed to form a thin layer of blood to provide fibrin naturally. A thin conjunctivolimbal autograft taken from superotemporal area was placed on the scleral bed with no glue/suture and waited for fifteen minutes for natural haemostasis. Patients were followed for 6 months postoperatively for any complications.

\section{RESULTS}

In our study from June 2014 to June 2015, 30 eyes subjected to pterygium excision with no glue/suture conjunctival autograft surgery were followed up for a period of 6 to 9 months. Cosmesis was excellent in 28 cases as graft was well taken and patients were happy, 2 patients had graft retraction at first post-operative week and regrafting was done. No recurrence was seen during this period.

\section{CONCLUSION}

Pterygium excision with no glue, no suture conjunctival autograft surgery is a simple surgery, cost effective with better cosmetic results with less complication.

\section{KEYWORDS}

Pterygium, Pterygium Excision with No Glue, Conjunctival Autograft.

HOW TO CITE THIS ARTICLE: Suma C, Manjula YM. A study of no suture, no glue conjunctival autograft surgery for pterygium. J. Evolution Med. Dent. Sci. 2017;6(8):644-646, DOI: 10.14260/Jemds/2017/138

\section{BACKGROUND}

Pterygium is a triangular fibrovascular subepithelial ingrowth of degenerative bulbar conjunctival tissue over the limbus onto the cornea ${ }^{1}$ probably resulting from limbal stem cell deficiency, generally situated on the nasal side. It sometimes occurs both nasally and temporally, and rarely only on the temporal side. Pterygium is more frequent in areas with more ultraviolet radiation, ${ }^{2}$ in hot, dry, windy, dusty, and smoky environments. ${ }^{3,4}$

Histologically, pterygium is characterised by hyaloid degeneration of conjunctival stroma, with accumulation of eosinophilic deposits together with intense fibroblastic proliferation and a rich vascular supply. Degenerated type 1 and type 4 collagen fibres have also been described. ${ }^{5}$

In addition to the obvious cosmetic concerns, it can induce corneal astigmatism. The induced corneal astigmatism may cause significant visual impairment and may require surgery.

Surgical removal is the treatment of choice. Many techniques have been suggested, as have adjunct therapies

Financial or Other, Competing Interest: None.

Submission 18-11-2016, Peer Review 14-01-2017,

Acceptance 19-01-2017, Published 25-01-2017.

Corresponding Author:

Dr. Suma $C$

Door No. 71, Lal Bagh,

Fort Road, Doddamavalli,

Bangalore -560004.

E-mail:drsumi13@gmail.com

DOI: $10.14260 /$ jemds $/ 2017 / 138$

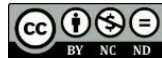

such as B radiation, ThioTEPA, 5-FU, and mitomycin C. High recurrence rates are weighted against eye threatening postoperative complications. Autologous conjunctival grafting seems to be the best method, giving both low recurrence rate and high safety. ${ }^{6}$

Sutures or glue is used to affix the conjunctival autograft after excision of the pterygium. Recently, a new technique of using patient's own blood present at the graft bed to fix the graft has been introduced. Sutures and glue being foreign materials are associated with complications such as infection, granuloma formation, chronic inflammation, hypersensitivity reactions or recurrence. ${ }^{7}$ This technique is also cost effective when compared to the techniques using sutures or glue.

Recurrence is a problem with pterygium surgeries. This has been significantly reduced with the introduction of the fixation of conjunctival autograft after pterygium excision. ${ }^{8}$ The rate of recurrence with sutures is approximately 15\%, while it is approximately $10-15 \%$ with glue. ${ }^{9}$

In this study, we aim to find out whether this new technique of a sutureless and glue-free graft is associated with any complications such as graft dehiscence, loss of graft and recurrence.

\section{MATERIALS AND METHODS}

This was a prospective interventional study. All patients with pterygium attending the ophthalmology outpatients department of BGS GIMS Hospital from June 2014 to June 2015 were included in the study. Indications for pterygium surgery were:

a. Progressive pterygium either invading or threatening visual axis. 
b. Visual impairment due to astigmatism.

c. Irritation and inflammation.

d. Restricted movements.

e. Cosmetic. Patients having Grade II, III and IV progressive pterygium were included in the study.

Patients with ocular pathology other than refractive error such as history of previous ocular surgery (except pterygium surgery), trauma, pseudopterygium and atrophic pterygium were excluded from the study. Written informed consent was obtained from all the participants. All methods adhered to the tenets of the Declaration of Helsinki Principles for research in human subjects. The study was approved by the Institutional Research Ethics Committee.

All patients went through general ophthalmic examination. Pterygium was graded depending on the extent of corneal involvement.

Grade I - crossing the limbus,

Grade II - midway between limbus and pupil,

Grade III- reaching up to pupillary margin,

Grade IV - crossing pupillary margin. Before the surgery, a comprehensive investigation was done including patient's age, gender, medical, and ocular history. Routine investigations (blood sugar levels both fasting and postprandial, urine routine and microscopy, haemogram and electrocardiography) and preanaesthetic check-ups were done. Best corrected visual acuity measurement, applanation tonometry, slit-lamp examination, and anterior segment photography were performed preoperatively and postoperatively at each visit. Probe test was done to rule out pseudopterygium.

This surgical technique was essentially similar to that described by de Wit et al. ${ }^{7}$ Surgery was done under peribulbar anaesthesia with good orbicularis oculi akinesia. Superior rectus bridle suture was taken which helped in obtaining a good conjunctival graft from 12 0'clock position. The body of the pterygium was dissected $2-3 \mathrm{~mm}$ from the limbus down to the bare sclera and reflected over the cornea. The pterygium head and cap were avulsed using artery forceps, followed by careful excision of the corneal remnants. During avulsion of the pterygium head, counter traction was applied with a cotton bud. Only thickened portions of the conjunctiva and the immediate adjacent and subjacent Tenon's capsule showing tortuous vasculature were excised. Excessive dissection of Tenon's was avoided. Wherever possible, haemostasis was allowed to occur spontaneously without the use of cautery. The size of the defect in $\mathrm{mm}^{2}$ was measured with Castroviejo callipers. Careful dissection between graft conjunctiva and Tenon's layer was done while fashioning the $0.5 \mathrm{~mm}$ oversized conjunctivolimbal graft from the superotemporal bulbar conjunctiva. The limbal edge of the graft was carefully positioned at the host limbal tissue edge. We did not make any attempt to directly close the full extent of the wound, allowing natural graft positioning without tension. The scleral bed was viewed through the transparent conjunctiva. To ensure that the residual bleeding does not lift the graft, small central haemorrhages were tamponaded with direct compression using non-toothed forceps until haemostasis was achieved. The stabilisation of the graft was tested centrally and on each free edge to ensure firm adherence to the sclera (Fig A). Surgery time was noted from the first incision until the lid speculum was removed. Eye patch was given and removed after 24 hours of surgery. Postoperatively, antibiotic-steroid eye drops (ofloxacin and prednisolone acetate) were given 4 times a day initially and tapered over 6 weeks. Along with these drops, lubricating eye ointment (hydroxypropyl methylcellulose $2 \%$ ) was also given to patients for 1-2 weeks. Lubricating eye drops carboxymethyl cellulose $0.5 \%$ were given for 1 -month postoperatively.

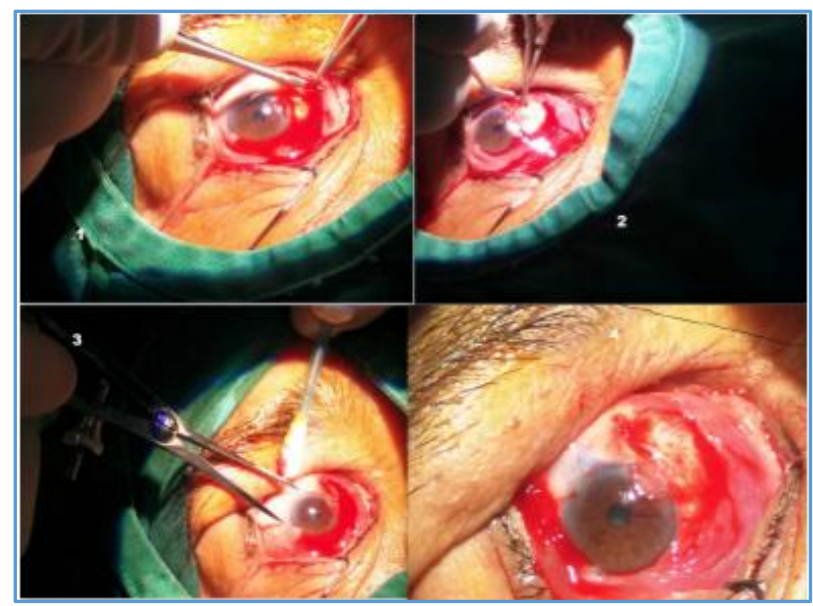

\section{Figure A showing \\ 1) Excision of Pterygium; \\ 2) Preparing Scleral Bed; \\ 3) Measuring donor site for Autograft; \\ 4) Conjunctival Autograft at Recipient Scleral Bed}

Surgical duration was recorded and the patients were followed-up on the first day after surgery and then at 8th day, 1-month, 3 months, 6 months and 9 months postoperatively.

\section{RESULTS}

In our study, we included 30 eyes of 30 patients with age group ranging from 20 to 50 years (fig B). There were 21 female and 9 male (fig $\mathrm{C}$ ) patients among which 18 right eyes and 12 left eyes (table 1) were affected and operated with no suture, no glue conjunctival autograft after surgical excision of pterygium. All patients had primary nasal pterygium and signed informed consent. Mean surgical time was $15 \mathrm{~min}$. (10- 20 min.) In our study, it was observed that pterygium was more common among female individuals and those who were exposed to more sunlight.

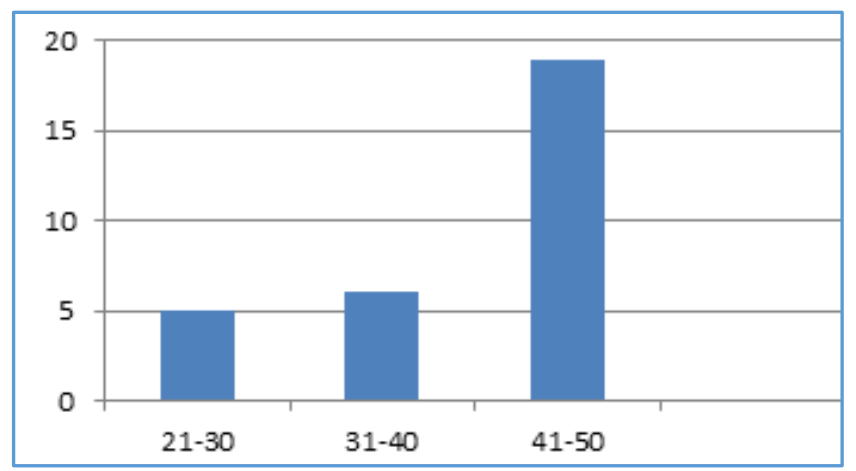

Figure B. Showing Age Distribution of the Patients 


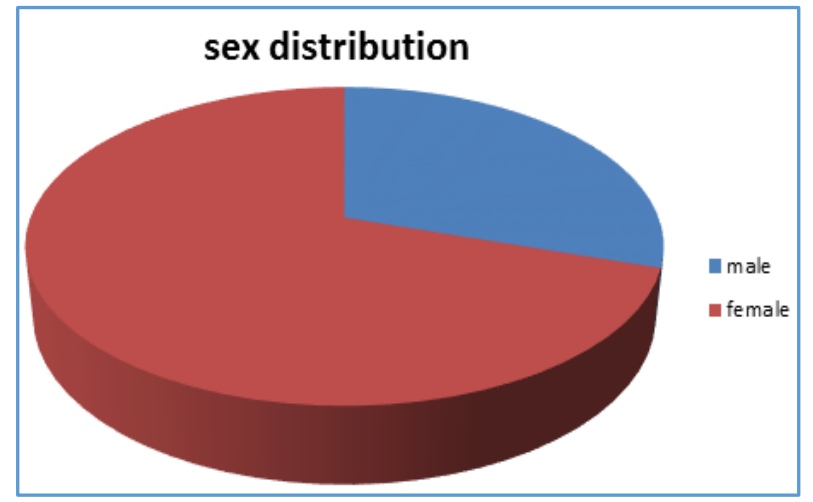

Figure C. Showing Sex Distribution

\begin{tabular}{|c|c|}
\hline Right Eye & Left Eye \\
\hline 18 & 12 \\
\hline \multicolumn{2}{|c|}{ Table 1. Showing Laterality of Pterygium } \\
\hline
\end{tabular}

28 out of 30 operated eyes had taken graft with good cosmetic outcome. 2 cases had graft displacement on 1 st postoperative day. The graft was repositioned in these 2 cases. No further displacement was observed after repositioning. No other significant postoperative complications occurred that warranted further treatment.

\section{DISCUSSION}

Current surgical methods to prevent pterygium recurrence include conjunctival autograft, limbal and limbal-conjunctival transplant, conjunctival flap and conjunctival rotation autograft surgery, amniotic membrane transplant, cultivated conjunctival transplant, lamellar keratoplasty, and the use of fibrin glue. All these techniques involve the use of sutures or fibrin glue and are therefore vulnerable to associated complications. ${ }^{10}$ The presence of sutures may lead to prolonged wound healing and fibrosis.6,11 Subsequent complications such as pyogenic granuloma formation are easily treated; others such as symblepharon formation, forniceal contracture, ocular motility restriction, diplopia, scleral necrosis, and infection are much more difficult to manage and may be sight threatening. ${ }^{22,13}$

This technique uses patient's own blood for fixation of the conjunctival or conjunctivolimbal autograft. It avoids the use of foreign materials such as suture and glue associated with increased inflammation, infection and hypersensitivity reactions. This technique is also cost effective. In 2010, de Wit et al $^{7}$ presented a case series describing a simple technique of using a sutureless and glue-free technique previously described by one of the authors, 14 to fix conjunctivolimbal autograft using naturally occurring fibrin at the bare scleral wound site.

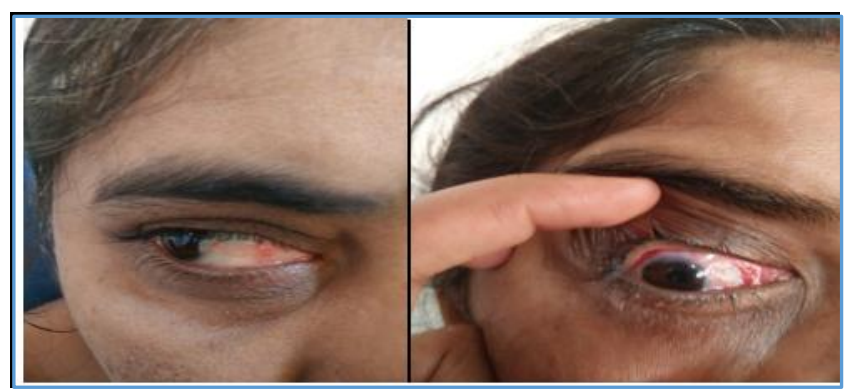

Figure D. Preoperative and 1 ${ }^{\text {st }}$ Post-operative Status

\section{CONCLUSION}

This technique is simple, cost effective with less complications and requires less surgical time as compared to other techniques like conjunctival autograft using sutures or glue. The procedure is also patient friendly and more comfortable in postoperative period. As our study followup period was of shorter period of 6 months, long term followup is necessary to know about long term complications and reliability.

\section{REFERENCES}

[1] Garg A. Clinical signs and symptoms of pterygium. In: Garg A, El Toukhy E, Nassaralla BA, et al. (edr). Surgical and medical management of pterygium. $1^{\text {st }}$ edn. India: Publisher Jaypee Brothers Medical Publisher 2009.

[2] Moran DJ, Hollows FC. Pterygium and ultraviolet radiation: a positive correlation. Br J Ophthalmol 1984;68(5):343-6.

[3] Nakaishi H, Yamamoto $M$, Ishida $M$, et al. Pingueculae and pterygia in motorcycle policemen. Ind Health 1997;35(3):325-9.

[4] Norn M, Franck C. Long-term changes in the outer part of the eye in welders. Prevalence of spheroid degeneration, pinguecula, pterygium, and corneal cicatrices. Acta Ophthalmol (Copenh) 1991;69(3):3826.

[5] Austin P, Jakobiec FA, Iwamoto T. Elastodysplasia and elastodystrophy as the pathologic bases of ocular pterygia and pinguecula. Ophthalmology 1983;90(1):96-109.

[6] Koranyi G, Seregard S, Kopp ED. Cut and paste: a no suture, small incision approach to pterygium surgery. Br J Ophthalmol 2004;88:911-4.

[7] De Wit D, Athanasiadis I, Sharma A, et al. Sutureless and glue-free conjunctival autograft in pterygium surgery: a case series. Eye (Lond) 2010;24(9):1474-7.

[8] Kenyon KR, Wagoner MD, Hettinger ME. Conjunctival autograft transplantation for advanced and recurrent pterygium. Ophthalmology 1985;92(11):1461-70.

[9] Shaw J. Clinical update: cornea new approach emerges for pterygium surgery. American Academy of Ophthalmology [Eyenet]. Last accessed on 2013 Oct 10. Available from: http://www.aao.org/publications/ eyenet/201202/ upload/New-Approach-Emerges-forPterygium-Surgery-PDF.pdf.

[10] Ang LP, Chua JL, Tan DT. Current concepts and techniques in pterygium treatment. Curr Opin Ophthalmol 2007;18(4):308-13.

[11] Allan BD, Short P, Crawford GJ, et al. Pterygium excision with conjunctival autografting: an effective and safe technique. Br J Ophthalmol 1993;77(11):698-701.

[12] Solomon A, Pires RT, Tseng SC. Amniotic membrane transplantation after extensive removal of primary and recurrent pterygia. Ophthalmology 2001;108(3):44960.

[13] Vrabec MP, Weisenthal RW, Elsing SH. Subconjunctival fibrosis after conjunctival autograft. Cornea 1993;12(2):181-3.

[14] Sharma A, Moore J. Autologous fibrin glue for pterygium surgery with conjunctival autograft. Cont Lens Anterior Eye 2009;32(5):209. 